\title{
A Study of Head and Neck Cancer Patients with Reference to Tobacco Use, Gender, and Subsite Distribution
}

\author{
Richa Chauhan ${ }^{1}$ Vinita Trivedi ${ }^{1}$ Rita Rani ${ }^{1} \quad$ Usha Singh ${ }^{1}$
}

${ }^{1}$ Department of Radiotherapy, Mahavir Cancer Sansthan, Patna, Bihar, India
Address for correspondence Richa Chauhan, DNB, Mahavir Cancer Sansthan, Patna, Bihar, India (e-mail: chauhan_richa@outlook.com).

South Asian J Cancer 2022;11(1):46-51.

Abstract

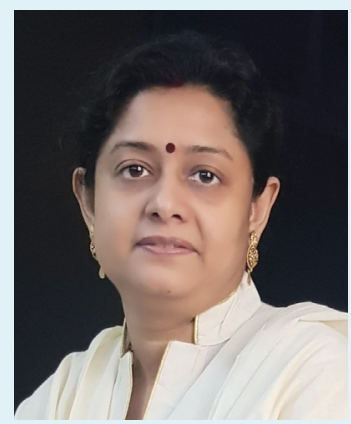

Richa Chauhan
Context Head and neck cancer (HNC) is very common in India, constituting $30 \%$ of all the cancers because of the widespread use of tobacco across India. The prevalence and pattern of tobacco use vary in different regions and states of the country. Although predominantly seen in males, studies have reported that the male-to-female ratio varies worldwide and also by anatomical subsite.

Aims This study was done with an aim to determine the difference in pattern and prevalence of tobacco use in male and female patients with HNCs and compare them with different subsites' involvement in our region.

Methods and Materials This is a retrospective analysis of 500 consecutive biopsyproven HNC patients from a large comprehensive cancer hospital from Bihar during the period of January 2019 to June 2019. Data collected for the study included age, gender, site of the disease, and use of tobacco. The categorical data were analyzed by a chisquare test using SPSS (version 16).

Results Our study showed a male-to-female ratio of 8.43:1 with tobacco addiction in $84.40 \%$ patients. Smokeless tobacco was used by $52.20 \%$, combustible form by $12.80 \%$, and both by $19.40 \%$ of the patients. Tobacco use was seen in $87.25 \%$ of male patients as compared with only $60.38 \%$ of female patients ( $p$-value $=0.0001)$. Oral cavity cancer was seen in $60.85 \%$ of male patients and $37.74 \%$ of female patients ( $p$-value $=0.0012$ ), whereas oropharyngeal cancer was seen in only $11.63 \%$ of male patients as compared with $25.83 \%$ of female patients ( $p$-value $=0.0008$ ). The subsite analysis showed that in

Keywords

- tobacco

- male

- female

- oral cavity

- oropharynx patients with oral cavity cancers, no addiction was found in only $10.29 \%$ of male patients as compared with $30 \%$ of the female patients ( $p$-value $=0.008$ ).

Conclusions Our study confirms a high prevalence of tobacco use among HNC patients. So, we need to continue our efforts to create awareness against tobacco use. Besides, there is also a need for more studies to look into other etiological factors among nontobacco users.
DOI https://doi.org/10.1055/s-0041-1740601 ISSN 2278-330X

How to cite this article: Chauhan R, Trivedi V, Rani R, et al. A Study of Head and Neck Cancer Patients with Reference to Tobacco Use, Gender, and Subsite Distribution South Asian J Cancer 2022;11(1):46-51. (c) 2022. MedIntel Services Pvt Ltd. All rights reserved.

This is an open access article published by Thieme under the terms of the Creative Commons Attribution-NonDerivative-NonCommercial-License, permitting copying and reproduction so long as the original work is given appropriate credit. Contents may not be used for commercial purposes, or adapted, remixed, transformed or built upon. (https://creativecommons.org/licenses/by-nc-nd/ 4.0/)

Thieme Medical and Scientific Publishers Pvt. Ltd., A-12, 2nd Floor, Sector 2, Noida-201301 UP, India 


\section{Introduction}

Worldwide, head and neck cancer (HNC) is the seventh most common cancer overall (the fifth most common in men and the 12 th most common in women), accounting for an estimated 888,000 new cases and 453,000 deaths in 2018. ${ }^{1}$ HNCs originate from squamous cells located in the mucosal epithelium inside the head and neck and are further classified by the anatomical area in which they arise. Head and neck squamous cell carcinoma (HNSCC) includes tumors of the oral cavity, nasopharynx, oropharynx, hypopharynx, and larynx. ${ }^{2}$ Overall $57.5 \%$ of global HNCs occur in Asia, especially in India where it accounts for $30 \%$ of all cancers. ${ }^{3,4}$ With $1,19,992$ new cases and 72,616 deaths due to oral cancers in 2018, India has the highest oral cavity cancer patients in the world. ${ }^{1}$ This could be related to the widespread use of tobacco in India. ${ }^{5}$ Tobacco use has been identified as a risk factor in 80 to $90 \%$ of patients of oral cancer. ${ }^{6}$ According to the recent Global Adult Tobacco Survey data, $42.4 \%$ of men, $14.2 \%$ of women, and $28.6 \%$ ( 266.8 million) of all adults in India currently use tobacco. ${ }^{7}$ Tobacco use in India is characterized by a high prevalence of combustible (in the form of smoking) and smokeless tobacco use, with dual use also contributing a noticeable proportion. ${ }^{8}$ Further, India's tobacco problem is very complex, with a large use of a variety of smoking forms and smokeless tobacco products. Combustible tobacco includes beedis, cigarettes, cigars, tobacco rolled in maize leaf and newspaper, hookah, pipes, chillum, and chutta. Smokeless tobacco includes tobacco leaf, betel quid with tobacco, khaini or tobacco lime mixture, gutkha, pan masala with zarda, gul, gudaku, and mishri. ${ }^{9-11}$ The prevalence and pattern of tobacco use vary in different regions and states of the country, which ranged from $9.7 \%$ in Goa to $64.5 \%$ in Tripura in 2016 to 2017. ${ }^{7}$ The state of Bihar also has a high prevalence of use of tobacco, especially that of chewing tobacco. ${ }^{7}$ However, there are few studies showing the prevalence and pattern of tobacco use among $\mathrm{HNC}$ patients of the state. Further, HNCs are predominantly seen in males, but the male-to-female ratio varies worldwide and also by anatomical site. ${ }^{12-14}$ Therefore, this study was done with an aim to determine the difference in pattern and prevalence of tobacco use in male and female patients with HNCs and compare them with different subsites' involvement.
Table 1 Gender wise distribution of head and neck cancer patients

\begin{tabular}{|l|l|l|l|}
\hline Gender & $\begin{array}{l}\text { Total No. } \\
\text { of patients }\end{array}$ & Percentage (\%) & Ratio \\
\hline Male & 447 & $89.40 \%$ & 8.43 \\
\hline Female & 53 & $10.60 \%$ & 1 \\
\hline
\end{tabular}

\section{Materials and Method}

This is a retrospective analysis of 500 consecutive biopsyproven HNC patients of Mahavir Cancer Sansthan, Patna, who reported during the period of January 2019 to June 2019. The subsites included in the study were oral cavity, oropharynx, hypopharynx, nasopharynx, and larynx. All the patients had squamous cell carcinoma. Data collected for the study included age, gender, site of the disease, and use of tobacco.

Data were entered in Microsoft Excel and the categorical data were analyzed by a chi-square test using SPSS (version 16). The association of tobacco use with gender and subsite of cancer was reviewed and compared. A $p$-value of less than 0.05 was accepted to be statistically significant.

\section{Results}

A male predominance was seen with a male-to-female ratio of 8.43:1. Among the 500 patients, 447 (89.4\%) were males and only $53(10.6 \%)$ were females. The age range of the patients was from 26 to 84 years. The most common age group was from 51 to 60 years followed by 61 to 70 years, 41 to 50 years, and 31 to 40 years with $26.60,21.60,21.40$, and $18.40 \%$ of the patients, respectively. A similar pattern of age distribution was seen among male patients. However, among the female patients, majority belonged to the age group of 41 to 70 years with only $3.77 \%$ of the patients in the age group of 31 to 40 years. This difference in age pattern was not statistically significant ( $p$-value $=0.066 ;-$ Tables 1 and 2 ).

Tobacco addiction in any form was seen in $422(84.40 \%)$ out of the 500 patients. The pattern of tobacco use showed that $52.20 \%$ of the patients used smokeless tobacco, $12.80 \%$

Table 2 Distribution of cases based on sex and age group $(n=500)$

\begin{tabular}{|c|c|c|c|c|}
\hline Age group & Total No. of patients, $\boldsymbol{n}(\%)$ & Male, $n(\%)^{a}$ & Female, $n(\%)^{b}$ & $p$-Value ${ }^{c}$ \\
\hline $20-30$ & $20(4.00 \%)$ & $19(4.25 \%)$ & 1 (1.89\%) & \multirow[t]{7}{*}{0.066} \\
\hline $31-40$ & $92(18.40 \%)$ & $90(20.13 \%)$ & 2 (3.77\%) & \\
\hline $41-50$ & $107(21.40 \%)$ & $91(20.36 \%)$ & $16(30.19 \%)$ & \\
\hline $51-60$ & $133(26.60 \%)$ & $116(25.95 \%)$ & $17(32.08 \%)$ & \\
\hline $61-70$ & 108 (21.60\%) & 94 (21.03\%) & $14(26.42 \%)$ & \\
\hline $71-80$ & $34(6.80 \%)$ & $31(6.94 \%)$ & $3(5.66 \%)$ & \\
\hline $81-90$ & $6(1.20 \%)$ & $6(1.34 \%)$ & 0 (0.00\%) & \\
\hline
\end{tabular}

apercentage of all male age groups.

bercentage of all female age groups.

${ }^{c} p$-Value obtained by a chi-square test. 
Table 3 Distribution of habits according to the gender $(n=500)$

\begin{tabular}{|l|l|l|l|l|}
\hline Group & Total No. of patients $(\boldsymbol{n}=\mathbf{5 0 0})$ & Male $(\boldsymbol{n}=447), \boldsymbol{n}(\%)^{\mathrm{a}}$ & ${\text { Female }(\boldsymbol{n}=53), \boldsymbol{n}(\%)^{\mathrm{b}}}^{p_{\text {-Value }}}$ \\
\hline No addiction & $78(15.60 \%)$ & $57(12.75 \%)$ & $21(39.62 \%)$ & 0.0001 \\
\hline Smokeless & $261(52.20 \%)$ & $249(55.70 \%)$ & $12(22.64 \%)$ & 0.0001 \\
\hline Smoking & $64(12.80 \%)$ & $51(11.41 \%)$ & $13(24.53 \%)$ & 0.0069 \\
\hline Both & $97(19.40 \%)$ & $90(20.13 \%)$ & $7(13.21 \%)$ & 0.2279 \\
\hline
\end{tabular}

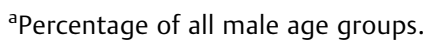

bercentage of all female age groups.

${ }^{c} p$-Value obtained by a chi-square test.

smoked, and 19.40\% used both smokeless and smoking tobacco. In male patients, the addiction was seen in $87.25 \%$ of the patients as compared with only $60.38 \%$ of female patients, with a highly significant $p$-value of 0.0001 . Use of smokeless tobacco was the most common addiction seen in $55.70 \%$ of male patients, whereas in the female population, beedi smoking was the most common form of tobacco addiction, seen in $24.53 \%$ of the patients. Use of chewable or smokeless tobacco was seen in only $22.64 \%$ of the female patients as compared with $55.70 \%$ of male patients with a significant $p$-value of 0.0001 (-Table 3 ).

Oral cavity was the most common site of disease, seen in $58.4 \%$ of the patients followed by larynx, oropharynx, hypopharynx, and nasopharynx in $17.2,13.4,7$, and $4 \%$ of the patients, respectively. The incidence of oral cancer further increased to $60.84 \%$ in the male patients as compared with only $37.74 \%$ in the female patients ( $p$-value $=0.0012$ ). However, the female patients showed a high incidence of oropharyngeal cancer as compared with the male patients, $28.30 \mathrm{vs}$. $11.63 \%$ ( $p$-value $=0.0008$; - Table 4$)$.

The subsite analysis showed that in patients of oral cavity cancers, no addiction was found in only $10.29 \%$ of male patients as compared with $30 \%$ of the female patients ( $p$ value $=0.008$ ). Use of smokeless tobacco was found in $62.50 \%$ of the male patients and in $45 \%$ of the female patients ( $p$ value $=0.1209$ ). Prevalence of smoking and smoking with the use of smokeless tobacco was comparable in both groups of the patients ( - Table 5 ).

In the laryngeal subsite, two-thirds of the female patients had no addiction as compared with only $13.16 \%$ of male patients without any addiction $(p$-value $=0.0001)$. None of the female patients used smokeless tobacco in this group as compared with $47.37 \%$ of their male counterparts ( $p$-value $=0.01$ ). Smoking was the only addiction seen in $25 \%$ of the female patients ( - Table 5 ).

The oropharyngeal subsite had the maximum number of male patients without any addiction. In this group, $23.08 \%$ of the patients had no addiction with almost comparable number of patients in the smokeless, smoking, and the group addicted to both smoking and smokeless tobacco. A total of $40 \%$ of the female patients in this group were addicted to smoking. However, there was no significant difference in the tobacco addiction pattern between male and female patients with oropharyngeal cancer. The hypopharyngeal subsite had $12.90 \%$ male patients with no addiction as compared with $50 \%$ of the female patients without any addiction. Smokeless tobacco was being used by $61.29 \%$ of the male patients. Smoking was the only addiction found in female patients. It was seen in $50 \%$ of the female patients as compared with $9.68 \%$ of the male patients ( $p$-value $=0.03$ ). The nasopharyngeal subsite had the least number of patients with a nonsignificant difference seen in the pattern of addiction in both male and female patients ( - Table 5 ).

\section{Discussion}

HNSCC is an epithelial malignant disease arising from the mucosa of the upper aerodigestive tract (oral cavity, larynx, oropharynx, and hypopharynx $)^{2}$ It has been classically described as a disease of older and middle-aged adults

Table 4 Distribution of cases based on the site of disease in male and female cancer patients $(n=500)$

\begin{tabular}{|c|c|c|c|c|c|}
\hline Site & Total No. of patients $(n=500)$ & Male $(n=447), n(\%)^{a}$ & Female $(n=53), n(\%)^{b}$ & $\mathrm{M} / \mathrm{F}$ ratio & $p$-Value ${ }^{c}$ \\
\hline OC & $292(58.40 \%)$ & $272(60.85 \%)$ & $20(37.74 \%)$ & 13.6 & 0.0012 \\
\hline OPX & $67(13.40 \%)$ & $52(11.63 \%)$ & $15(28.30 \%)$ & 3.46 & 0.0008 \\
\hline LNX & $86(17.20 \%)$ & $76(17.00 \%)$ & $10(18.87 \%)$ & 7.6 & 0.7336 \\
\hline HPX & $35(7.00 \%)$ & $31(6.94 \%)$ & $4(7.55 \%)$ & 7.75 & 0.8688 \\
\hline NPX & $20(4.00 \%)$ & $16(3.58 \%)$ & $4(7.55 \%)$ & 4 & 0.1634 \\
\hline
\end{tabular}

Abbreviation: HPX, hypopharynx; M/F, male/female; NPX, nasopharynx; OC, oral cavity; OPX, oropharynx; LNX, larynx.

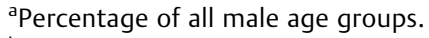

bercentage of all female age groups.

${ }^{c} p$-Value obtained by a chi-square test. 
Table 5 Distribution of habits according to the gender and subsites

\begin{tabular}{|l|l|l|l|l|}
\hline Site & Habit & Male & Female & -Value \\
\hline \multirow{5}{*}{ Oral cavity } & No addiction & $28(10.29 \%)$ & $6(30.00 \%)$ & 0.0080 \\
\cline { 2 - 5 } & Smokeless & $170(62.50 \%)$ & $9(45.00 \%)$ & 0.1209 \\
\cline { 2 - 5 } & Smoking & $23(8.46 \%)$ & $2(10.00 \%)$ & 0.8117 \\
\cline { 2 - 5 } & Both & $51(18.75 \%)$ & $3(15.00 \%)$ & 06767 \\
\hline \multirow{5}{*}{ Oropharynx } & No addiction & $12(23.08 \%)$ & $6(40.00 \%)$ & 0.1927 \\
\cline { 2 - 5 } & Smokeless & $15(28.85 \%)$ & $1(6.67 \%)$ & 0.0759 \\
\cline { 2 - 5 } & Smoking & $13(25.00 \%)$ & $6(40.00 \%)$ & 0.2562 \\
\cline { 2 - 5 } & Both & $12(23.08 \%)$ & $2(13.33 \%)$ & 0.4135 \\
\hline \multirow{5}{*}{ Larynx } & No addiction & $10(13.16 \%)$ & $6(75.00 \%)$ & 0.0001 \\
\cline { 2 - 5 } & Smokeless & $36(47.37 \%)$ & $0(0.00 \%)$ & 0.0100 \\
\cline { 2 - 5 } & Smoking & $12(15.79 \%)$ & $2(25.00 \%)$ & 0.5061 \\
\cline { 2 - 5 } & Both & $18(23.68 \%)$ & $0(0.00 \%)$ & 0.1204 \\
\hline & No addiction & $4(12.90 \%)$ & $2(50.00 \%)$ & 0.0639 \\
\cline { 2 - 5 } & Smokeless & $19(61.29 \%)$ & $0(0.00 \%)$ & 0.0206 \\
\cline { 2 - 5 } & Smoking & $3(9.68 \%)$ & $2(50.00 \%)$ & 0.0301 \\
\cline { 2 - 5 } & Both & $5(16.13 \%)$ & $0(0.00 \%)$ & 0.3856 \\
\hline \multirow{5}{*}{ Nasopharynx } & No addiction & $3(18.75 \%)$ & $1(25.00 \%)$ & 0.7799 \\
\cline { 2 - 5 } & Smokeless & $9(56.25 \%)$ & $2(50.00 \%)$ & 0.8222 \\
\cline { 2 - 5 } & Smoking & $0(0.00 \%)$ & $1(25.00 \%)$ & 0.0402 \\
\cline { 2 - 5 } & Both & $4(25.00 \%)$ & $0(0.00 \%)$ & 02636 \\
\hline
\end{tabular}

with a long history of tobacco use. ${ }^{15}$ Being a tobacco-related cancer and a high consumption of tobacco products among the male population in India, HNCs are more common in males than in females. Studies have reported a male-tofemale ratio ranging from 2:1 to 5:1 in Indian population. ${ }^{12}$ The gender-wise distribution of our study showed a male-tofemale ratio of $8.4: 1$, which is higher than those previously reported. The possible cause could be the social taboo associated with the use of tobacco among females in the state, which results in low prevalence of tobacco addiction. ${ }^{16}$ Another possible factor for a high prevalence of oral cancers among males than females is the difference in the working pattern seen in our state. Majority of the male population is involved in outdoor activities as they work as farmers or laborers, which means working in scorching sunlight for long hours. Oral cancer, especially lip cancer, has been related to sunlight exposure in many studies. ${ }^{17}$ International Agency for Research on Cancer has also recognized prolonged exposure to sun for long hours as a carcinogen for skin and lip cancers. ${ }^{18}$ The women of our state usually work indoor and do household chores, which protect them from prolonged exposure to direct sunrays.

Majority of our patients were in the age group of 41 to 70 years. Although the percentage of male population below the age of 40 was higher than that of the female patients, the difference seen in different age groups was not statistically significant $(p$-value $=0.66$ ). Many other studies have shown similar results and reported that HNC is more common in 4th to 6th decades of life. ${ }^{12,13}$ It has also been observed that males were presenting a decade earlier than females. ${ }^{19}$ Thus, we can say that the male preponderance and age of presentation seen in our study are in correlation with other studies.

Tobacco addiction was found in $84.40 \%$ of our patients. The gender-wise distribution of tobacco use showed a statistically significant higher addiction among male patients as compared with female patients, i.e., 87.25 vs. 60.38\% ( $p$ value $=0.0001)$. A recent study by Das et al from Northeast India reported that $82.9 \%$ of all HNCs in both genders were found to be associated with tobacco in any form. Their gender-wise analysis showed a total of $87.7 \%$ males and $64.6 \%$ females to be associated with tobacco habits, which are similar to our study results. ${ }^{15}$ A study by Kumar et al among North Indian population reported $97 \%$ of the patients being addicted to tobacco. Tobacco use has been reported to be prevalent among men, rural population, illiterates, and poor and vulnerable sections of the society. ${ }^{12}$

Overall, oral cavity was the most common site of cancer seen in $58.4 \%$ of our patients, followed by oropharynx, larynx, hypopharynx, and nasopharynx in $17.2,13.4,7$, and $4 \%$ of the patients, respectively. A gender-wise distribution of subsite involvement showed a statistically significant difference in the incidence of oral cavity and oropharyngeal cancer. Oral cavity cancer was seen in $60.85 \%$ of male patients as compared with only $37.74 \%$ of female patients ( $p$-value 
$=0.0012$ ). On the other hand, oropharyngeal cancer was seen in only $11.63 \%$ of male patients as compared with $25.83 \%$ of female patients ( $p$-value $=0.0008$ ). There was no statistically significant difference seen in other subsites.

This finding could probably be explained by the difference seen in the prevalence and pattern of tobacco use among our male and female patients. Among male patients, use of smokeless tobacco mainly in the form of khaini chewing was seen in $55.70 \%$ of cases followed by smoking in $11.41 \%$, and both in $20.13 \%$ cases. Smoking mostly in the form of beedi was the most common form of tobacco addiction seen in $24.53 \%$ of the female patients. Use of smokeless tobacco was seen in only $22.64 \%$ of the female patients. This difference in the pattern of tobacco use was statistically significant with a $p$-value of 0.0001 .

Our study shows that approximately $78 \%$ of all male patients used smokeless tobacco either alone or in combination with smoking as compared with only $36 \%$ of female patients. A review by Jethwa and Khariwala has reported a tremendous geographic variation in the type of tobacco product consumed worldwide. ${ }^{20}$ Approximately $90 \%$ of the world's smokeless tobacco consumption has been reported in Southeast Asia with nearly 100 million people using smokeless tobacco in India and Pakistan alone. ${ }^{21,22}$ According to Global Adult Tobacco Survey 2 survey, approximately $29.6 \%$ of men and only $12.8 \%$ of women currently use smokeless tobacco in India. ${ }^{7}$

Our observation of a preponderance of oral cavity cancers among all HNCs is in accordance to the fact that chewing tobacco has a strong correlation to oral cavity cancer as compared with other subsites. ${ }^{23,24}$ Goud et al had reported that oral cancers caused by chewing tobacco are common in India and some parts of the Indian subcontinent with their study showing a significant association ( $p$-value less than 0.001 ) between the use of Indian chewing tobacco and oral cancer. ${ }^{25}$ Pednekar et al in their Mumbai cohort study also reported that smokeless tobacco use was associated with cancers of the lip, oral cavity, pharynx, digestive, respiratory, and intrathoracic organs. ${ }^{26}$

In a survey conducted in 0.1 million households, the state of Bihar had the highest percentage $(57 \%)$ of households consuming smokeless tobacco. ${ }^{27}$ In another cross-sectional study from rural Bihar, smokeless tobacco use had 33\% prevalence with khaini (57\%) as the predominant choice. ${ }^{28}$

Smokeless tobacco contains $>30$ known carcinogens with predominance of nitrosamines, aromatic amines, polycyclic hydrocarbons, aldehydes, and metals. ${ }^{20}$ These carcinogens in tobacco undergo metabolic activation processes initiated by cytochrome p450 enzymes. Metabolic activation makes the carcinogens electrophilic which then react with DNA to form DNA adducts. When left unrepaired, DNA adducts can cause miscoding and permanent mutations which can activate oncogenes such as K-ras, or inactivate tumor suppressor genes such as p53 to initiate and promote carcinogenesis. ${ }^{29,30}$

Thus we see that the role and pathogenesis of smokeless tobacco in oral cavity cancer have been well studied. However, our study also reported approximately $40 \%$ of the female patients with no tobacco addiction. The female patients also had a statistically significantly higher prevalence of oropharyngeal cancer than male patients. In the past few years, strong evidence has accumulated that infection with certain human papillomaviruses (HPVs) is the cause for the increasing incidence of HNSCC despite a decrease in the use of tobacco and particularly for the oropharyngeal subsite. ${ }^{31}$ According to the recent World Cancer Report, 30.8\% of oropharyngeal cancers have been attributed to HPV infection as compared with only $2.2 \%$ for oral cavity and $2.4 \%$ for laryngeal cancers. ${ }^{32}$ Thus, HPV could be the most probable etiological agent in our female patients who are nontobacco users. Besides, other factors like poor oral hygiene, lichen planus, iron-deficiency anemia, poor diet, gastrointestinal reflux, and genetic predisposition also have a role in causing HNC, particularly in nontobacco users. ${ }^{33-35}$

The limitation of this study is that being retrospective in nature we could only analyze the categorical data we had at our disposal. Details regarding many other etiological factors like use of alcohol, poor oral hygiene, chronic oral infection, nutritional status, and sexual history for evaluating HPV infection risk were not available. Further, limited analyses could be done at subsites like larynx, hypopharynx, and nasopharynx because of a small number of female patients which further decreased when it was distributed according to subsites and tobacco use.

\section{Conclusion}

Our study confirms a high prevalence of tobacco use among HNC patients. Tobacco use is more common in males, particularly in the smokeless form. So, we need to continue our efforts to create awareness against tobacco use. In addition to this, there is also a need for more studies to look into etiological factors like HPV for HNC among nontobacco users. Good oral hygiene, proper treatment of benign oral lesions, healthy food, and lifestyle habits should also be recommended for prevention of HNCs.

\section{Source(s) of Support}

Nil.

\section{Conflicting Interest}

Nil.

\section{References}

1 Bray F, Ferlay J, Soerjomataram I, Siegel RL, Torre LA, Jemal A. Global cancer statistics 2018: GLOBOCAN estimates of incidence and mortality worldwide for 36 cancers in 185 countries. CA Cancer J Clin 2018;68(06):394-424

$2 \mathrm{NCI}$. Head and neck cancer. United States National Cancer Institute, National Institutes of Health 2018. Accessed March 22, 2021: www.cancer.gov/types/head-and-neck/head-neck-factsheet

3 Masud D, Gilbert P. Secure sterile head drape for head and neck surgery. J Plast Reconstr Aesthet Surg 2009;62(01):143-144

4 Kulkarni MK. Head and neck cancer burden in India. Int J Head Neck Surg 2013;4:29-35

5 Boffetta P, Hecht S, Gray N, Gupta P, Straif K. Smokeless tobacco and cancer. Lancet Oncol 2008;9(07):667-675 
6 Decker J, Goldstein JC. Risk factors in head and neck cancer. N Engl J Med 1982;306(19):1151-1155

7 Available at: WHO. Global Adult Tobacco Survey India; 2016-17. Accessed March 22, 2021: www.who.int/tobacco/surveillance/ survey/gats/ GATS_India_2016-17_FactSheet.pd. Accessed on December 10, 2021

8 Addala L, Pentapati CK, Reddy Thavanati PK, Anjaneyulu V, Sadhnani MD. Risk factor profiles of head and neck cancer patients of Andhra Pradesh, India. Indian J Cancer 2012;49(02):215-219

9 Reddy KS, Gupta PC, eds. Report on Tobacco Control in India. New Delhi, India: Ministry of Health and Family Welfare, Government of India; 2004

10 Adhikari A, De M. Toxic effects of betel quid. Int J Hum Genet 2013; 13:7-14

11 Stepanov I, Jensen J, Hatsukami D, Hecht SS. New and traditional smokeless tobacco: comparison of toxicant and carcinogen levels. Nicotine Tob Res 2008;10(12):1773-1782

12 Kumar A, Sharma A, Ahlawat B, Sharma S. Site specific effect of tobacco addiction in upper aerodigestive tract tumors: a retrospective clinicopathological study. ScientificWorldJournal 2014; 2014:460194

13 Malik A, Mishra A, Garg A, et al. Trends of oral cancer with regard to age, gender, and subsite over 16 years at a tertiary cancer center in India. Indian J Med Paediatr Oncol 2018;39:297-300

14 Lambert R, Sauvaget C, de Camargo Cancela M, Sankaranarayanan R. Epidemiology of cancer from the oral cavity and oropharynx. Eur J Gastroenterol Hepatol 2011;23(08):633-641

15 Das R, Kataki AC, Sharma JD, Baishya N, Kalita M, Krishnatreya M. A study of head and neck cancer patients with special reference to tobacco use and educational level. Clin Cancer Investig J 2017; 6:21-25

16 Pandey A, Singh A, Singh S, et al. Oral smokeless tobacco consumption pattern among rural Indian cancer patients: a prospective survey. South Asian J Cancer 2020;9(01):17-19

17 Kenborg L, Jørgensen AD, Budtz-Jørgensen E, Knudsen LE, Hansen J. Occupational exposure to the sun and risk of skin and lip cancer among male wage earners in Denmark: a population-based casecontrol study. Cancer Causes Control 2010;21(08):1347-1355

18 IARC. List of classifications: agents classified by the IARC Monographs, Volumes 1-124" IARC Monographs on the Evaluation of Risk to Humans. IARC 2019

19 Ologe FE, Adeniji KA, Segun-Busari S. Clinicopathological study of head and neck cancers in Ilorin, Nigeria. Trop Doct 2005;35(01):2-4

20 Jethwa AR, Khariwala SS. Tobacco-related carcinogenesis in head and neck cancer. Cancer Metastasis Rev 2017;36(03):411-423

21 Zhou J, Michaud DS, Langevin SM, McClean MD, Eliot M, Kelsey KT. Smokeless tobacco and risk of head and neck cancer: evidence from a case-control study in New England. Int J Cancer 2013;132 (08):1911-1917

$22 \mathrm{Ng}$ M, Freeman MK, Fleming TD, et al. Smoking prevalence and cigarette consumption in 187 countries, 1980-2012. JAMA 2014; 311(02):183-192

23 Siddiqi K, Shah S, Abbas SM, et al. Global burden of disease due to smokeless tobacco consumption in adults: analysis of data from 113 countries. BMC Med 2015;13:194

24 Coelho KR. Challenges of the oral cancer burden in India. J Cancer Epidemiol 2012;2012:701932

25 Goud ML, Mohapatra SC, Mohapatra P, Gaur SD, Pant GC, Knanna MN. Epidemiological correlates between consumption of Indian chewing tobacco and oral cancer. Eur J Epidemiol 1990;6(02): 219-222

26 Pednekar MS, Gupta PC, Yeole BB, Hébert JR. Association of tobacco habits, including bidi smoking, with overall and sitespecific cancer incidence: results from the Mumbai cohort study. Cancer Causes Control 2011;22(06):859-868

27 Agrawal S, Karan A, Selvaraj S, Bhan N, Subramanian SV, Millett C. Socio-economic patterning of tobacco use in Indian states. Int J Tuberc Lung Dis 2013;17(08):1110-1117

28 Sinha DN, Gupta PC, Pednekar MS. Tobacco use in a rural area of Bihar, India. Indian J Community Med 2003;28:167-170

29 Khariwala SS, Hatsukami D, Hecht SS. Tobacco carcinogen metabolites and DNA adducts as biomarkers in head and neck cancer: potential screening tools and prognostic indicators. Head Neck 2012;34(03):441-447

30 Basu R, Mandal S, Ghosh A, Poddar TK. Role of tobacco in the development of head and neck squamous cell carcinoma in an eastern Indian population. Asian Pac J Cancer Prev 2008;9(03): 381-386

31 IARC Working Group on the Evaluation of Carcinogenic Risks to Humans. Human papillomaviruses. IARC Monogr Eval Carcinog Risks Hum 2007;90:1-636

32 de Martel C, Plummer M, Vignat J, Franceschi S. Worldwide burden of cancer attributable to HPV by site, country and HPV type. Int J Cancer 2017;141(04):664-670

33 Toner M, O'Regan EM. Head and neck squamous cell carcinoma in the young: a spectrum or a distinct group? Part 1 . Head Neck Pathol 2009;3(03):246-248

34 Sturgis EM, Wei Q. Genetic susceptibility-molecular epidemiology of head and neck cancer. Curr Opin Oncol 2002;14(03): 310-317

35 Dahlstrom KR, Little JA, Zafereo ME, Lung M, Wei Q, Sturgis EM. Squamous cell carcinoma of the head and neck in never smokernever drinkers: a descriptive epidemiologic study. Head Neck 2008;30(01):75-84 